\title{
Scanning electron microscopy of the surface epithelium of the bovine endometrium
}

\author{
F. G. Kumro, E. V. O’Neil, L. A. Ciernia, J. G. N. Moraes, T. E. Spencer, and M. C. Lucy* \\ Division of Animal Sciences, University of Missouri, Columbia 65211
}

\begin{abstract}
The surface epithelium of the bovine endometrium comprises at least 2 cell types (ciliated cells and secretory cells with microvilli), but their distribution and morphological changes over the estrous cycle are poorly understood. The objective was to quantify the number of ciliated cells and assess morphological changes in secretory cells on the uterine surface epithelium during the estrous cycle. Caruncular endometrium (CAR) and intercaruncular endometrium (ICAR) samples were collected from the uterine body, the horn ipsilateral to the corpus luteum or dominant follicle (H-CL/DF), and the horn contralateral to the corpus luteum or dominant follicle (H-NCL/NDF) from heifers following slaughter on d 0 (estrus; $\mathrm{n}=5$ ) or d 14 (mid-luteal phase; $\mathrm{n}=$ 5 ) of the estrous cycle. Samples were prepared for scanning electron microscopy at $1,000 \times$ magnification. Four to 10 fields $(256 \times 225 \mu \mathrm{m})$ for each sample were examined ( $\mathrm{n}=567$ images). The number of ciliated cells was counted and the surface was scored for the morphology of the secretory cells $(0=$ absence of microvilli on surface; $3=100 \%$ of surface covered with microvilli). Ciliated cells were present in both the CAR and ICAR regions. The number of ciliated cells per field increased from d 0 to 14 in CAR and decreased from d 0 to14 in ICAR. The scanning electron microscopy revealed a general lack of uniformity in the lawn of microvilli on the surface of the endometrium. Based on the scores, approximately $25 \%$ of the fields had a surface that was $<50 \%$ covered by microvilli. Depletion of microvilli may be explained by a normal process where apical protrusions are formed and either regress back into the cell surface or break to release their contents into the uterine lumen. These studies support the hypothesis that the surface of the luminal epithelium changes during the estrous cycle through a process that involves remodeling of the apical surface. The morphology of
\end{abstract}

Received May 6, 2020.

Accepted July 15, 2020.

*Corresponding author: lucym@missouri.edu the apical surface may have a key role in governing pregnancy establishment.

Key words: endometrium, scanning electron microscopy, microvilli, cilia

\section{INTRODUCTION}

The bovine endometrium comprises several different cell types with unique functions that support estrous cyclicity and pregnancy [reviewed by Spencer et al. (2016), Sandra et al. (2017), and Ott (2019)]. Stromal cells support uterine function through their actions on the epithelium (Hantak et al., 2014). The uterine epithelium includes the luminal epithelium (LE) and the glandular epithelium (GE). The LE lines the uterine lumen across aglandular caruncular endometrium (CAR) and the intercaruncular endometrium (ICAR) where uterine glands invaginate the uterine stroma (Hafez and Ludwig, 1977). Both the GE and the LE perform essential functions with respect to the regulation of estrous cyclicity, early embryo development, maternal recognition of pregnancy, and ultimately the establishment of pregnancy (Spencer et al., 2016; Sandra et al., 2017; Ott, 2019).

The GE and LE comprise ciliated cells, secretory cells with microvilli, and numerous immune cell types (Hafez and Ludwig, 1977; Akbalik et al., 2018). The ciliated cells are functionally different from cells containing microvilli. Cilia possess a typical $9+2$ microtubule arrangement and are capable of coordinated movement (Spassky and Meunier, 2017). In the oviduct, cilia are believed to create a current to move the oocyte down the oviduct and toward the site of fertilization (Koyama et al., 2019). Ciliated cells are also found in the GE and perhaps function in the transport of histotroph out of the glands and into the uterine lumen (Kelleher et al., 2019). The function of the ciliated cells that are found in the LE is unclear. Cells with microvilli are found in the glands and are the predominant cell type in the LE (Guillomot and Guay, 1982; Guillomot, 1995). The microvilli increase the apical surface area to increase absorption and secretion of small molecules (Walton et al., 2016; Moraes et al., 2020a,b) and are critical 
for embryo implantation (Bazer et al., 2009). Uterine receptivity for pregnancy may in part be explained by the distribution and functional capacity of microvilli.

In postpartum cows, the functional and morphological integrity of the uterus is re-established during the process of uterine involution (Sheldon, 2004). The healthy uterus will remodel to a normal size within 30 $\mathrm{d}$, and cows typically recover full fertility by approximately $60 \mathrm{~d}$ postpartum. Restoration of fertility can be delayed in cows with uterine disease where bacterial infection is unresolved and there is chronic inflammation of the uterus (Wathes, 2012; LeBlanc, 2014; Gilbert, 2019). Histological examination of endometrium demonstrated that infection can induce lesions and alter the structural integrity of the endometrium (Dadarwal et al., 2017). Abnormal epithelial cell morphology and physiology caused by bacterial infection, therefore, may be an underlying cause of long-term infertility in dairy cows that experience uterine disease early postpartum.

The bovine uterus is typically studied in cross-section and at the level of light microscopy without sufficient detail to examine the unique cell types or detailed changes in their morphology. Ciliated cells and cells with microvilli in the LE as well as oviduct have been studied using scanning electron microscopy in ruminants including cattle (Fathalla et al., 1975; Guillomot and Guay, 1982; Hyttel, 1985; Almeida et al., 1986; Wrobel et al., 1993; Yániz et al., 2000), sheep (Guillomot et al., 1981), and roe deer (Aitken, 1975). Most of those studies were published almost 4 decades ago and did not attempt to quantify changes in the surface of the bovine uterus within CAR and ICAR regions of the horn or body or on different days of the estrous cycle. As a prelude to further studies of the uterus of postpartum cows recovering from uterine disease, we studied the morphology of a normal, nondiseased endometrial surface of dairy heifers. The objective was to quantify the number of ciliated cells and assess morphological changes on the uterine surface epithelium including microvilli during the estrous cycle. Different regions of the uterus (body and horn) were also examined to determine whether there were regional differences in the uterine surface.

\section{MATERIALS AND METHODS}

Study procedures were approved by the University of Missouri Institutional Animal Care and Use Committee (protocol no. 9635). Holstein heifers (12-14 mo old) were treated with an intramuscular injection of $\mathrm{PGF}_{2 \alpha}$ ( $5 \mathrm{~mL}$ of Lutalyse, $25 \mathrm{mg}$ of dinoprost tromethamine; Zoetis Inc., Florham Park, NJ) to induce estrus. Heifers were humanely slaughtered by captive bolt stunning and exsanguination on the morning of the day of estrus
( $\mathrm{n}=5$ ) or the morning of $\mathrm{d} 14$ of the estrous cycle $(\mathrm{n}=5)$. Estrous heifers were slaughtered $48 \mathrm{~h}$ after the $\mathrm{PGF}_{2 \alpha}$ injection when they were beginning to show signs of estrus (mounting other heifers) and had either a fully $(\mathrm{n}=1)$ or partially $(\mathrm{n}=4)$ activated Estrotect patch (Rockway Inc., Spring Valley, WI). The uterus was removed, wrapped in surgical drape, placed on ice, and brought to a laboratory. The broad ligament was removed and the uterus was opened along its entire length to expose the endometrial surface of both uterine horns and uterine body. The presence of a regressed corpus luteum was confirmed (d 0 heifers), and the location of the presumptive ovulatory follicle (d 0 heifers) or the corpus luteum (d 14 heifers) was recorded. The exposed surface of the endometrium contained raised areas that were paler in color and regions between the raised areas (CAR and ICAR, respectively). The CAR and ICAR were collected from 3 locations: the uterine horn ipsilateral to the corpus luteum or dominant follicle (H-CL/DF), the horn contralateral to the corpus luteum or dominant follicle (H-NCL/NDF), and the body of the uterus (referred to throughout as "body") where the 2 horns were joined. Biopsies were prepared for scanning electron microscopy by the University of Missouri Electron Microscopy Core.

The excised samples were fixed with $2 \%$ formaldehyde and $2 \%$ glutaraldehyde in $0.1 \mathrm{M}$ sodium cacodylate buffer $(\mathrm{pH} 7.3)$ at $4^{\circ} \mathrm{C}$ until time for processing. When the biopsies were submitted for processing, they were postfixed in $1 \%$ osmium tetroxide, dehydrated in a graded ethanol series ( $70 \%$ to $80 \%$ to $95 \%$ to $100 \%$ ), and dried in an AutoSamdri 815 critical point dryer (Tousimis, Rockville, MD). Dried samples were mounted on aluminum stubs using double-sided carbon tape and coated with a 25-nm thin coat of platinum in an EMS 150 TES sputter coater (Electron Microscopy Sciences, Hatfield, PA). Secondary electron micrographs were recorded using an FEI Quanta 600F scanning electron microscope (ThermoFisher, Hillsboro, OR) at an acceleration voltage of $10 \mathrm{kV}$.

The sample set consisted of 10 heifers $(\mathrm{n}=5$ at $\mathrm{d} 0$ and $\mathrm{n}=5$ at $\mathrm{d}$ 14), 2 tissue types (CAR and ICAR), and 3 locations (H-CL/DF, H-NCL/NDF, and body) for a total of 60 samples. Four to 10 fields $(256 \times 225$ $\mu \mathrm{m})$ were selected at random for morphological evaluation for each of the 60 samples $(\mathrm{n}=567$ fields; average of 9.5 fields per sample). The number of ciliated cells were counted and the surface was scored for the completeness of the lawn of microvilli that covered the LE. The morphological score ranged from 0 (devoid of microvilli) to 3 (completely covered with microvilli). Intermediate scores were score 1 ( $>0$ but $<50 \%$ covered with microvilli) and $2(\geq 50$ but $<100 \%$ covered with microvilli; Figure 1). Data were analyzed using SAS 
9.4 (SAS Institute Inc., Cary, NC). The number of ciliated cells and morphology score of the surface (0 to 3 ) were averaged across fields for each of the 60 individual samples. The average number of ciliated cells and the average score were analyzed for the effects of sample location (H-CL/DF, H-NCL/NDF, or body), day of the estrous cycle (d 0 or 14), tissue type (CAR or ICAR), and the interactions using PROC MIXED of SAS. Cow nested within day was defined as random and was the experimental unit for the statistical analyses. The least squares means were separated using the PDIFF procedure. Significance was declared at $P<0.05$ unless stated otherwise.

\section{RESULTS AND DISCUSSION}

Scanning electron microscopy of the surface epithelium of the bovine endometrium allowed visualization of the structural morphology of the LE. At low magnifications we were able to confirm the abundance of glands in the ICAR and the absence of glands in the CAR (Figure 2A and B). The distribution of cilia was not uniform in nature but appeared to be sporadic (Figure 2A and $\mathrm{C}$ ) with the exception of gland openings where ciliated cells were highly concentrated (Figure 2D). Perhaps the uneven distribution of ciliated cells in the surface epithelium could be explained by migration of cells from the uterine glands and into the surface epithelium (LE). Ciliated cells were present in both the CAR and ICAR regions and on d 0 and 14. The number of ciliated cells was highly variable across heifers, with a range of 0 to 154 per field for CAR and 0 to 76 per field for ICAR. There was no effect of location on the number of ciliated cells per field (Table $1 ; P>$ 0.10 ). The number of ciliated cells per field was affected by an interaction of day and tissue type. The number of ciliated cells per field increased from d 0 to 14 in CAR and decreased from d 0 to14 in ICAR (Table 1; tissue type $\times$ day interaction; $P<0.002$ ). The functional significance of the numerical changes in the relatively sparse and highly variable population of ciliated cells in the bovine endometrium is unknown. Ciliated cells do not appear abundant enough to coordinate movement or flow of uterine contents but could perhaps provide for some mixing or movement of luminal fluid.

Epithelial cells with apical microvilli were the predominant cell type within the bovine LE (Figure $1 \mathrm{D}$ and F). Microvilli increase the area of the apical surface, allowing for greater secretion and absorption of molecules across the cell membrane. The surface of the LE is typically depicted with a uniform lawn of microvilli and a small number of interspersed ciliated cells. Observations of the ciliated cell population were consistent with this view, but our samples revealed a general lack of uniformity in the lawn of microvilli on the surface of the LE (Figure 1). Within the same tissue section, for example, we noted regions where almost all cells had microvilli (Figure 1D and F) and other regions where the apical surface of the cells appeared cratered with microvilli lining the apical junction between cells (Figure 1A and E). A microvilli scoring system was developed to quantify the observations (Figure 1). There were $84,58,235$, and 190 fields that scored $0,1,2$, or 3 , respectively, for the completeness of the lawn of microvilli. Based on the scores, approximately $25 \%$ of the fields that we observed had a surface that was $<50 \%$ covered by microvilli. The average score for individual heifers across all fields (both CAR and ICAR) ranged from $1.17 \pm 1.21$ to $2.54 \pm 0.57$ (mean $\pm \mathrm{SD}$; greater than 2-fold difference in average scores across heifers).

The body of the uterus had a lesser score compared with either the H-CL/DF or the H-NCL/NDF (Table 1; effect of location, $P<0.032)$. The CAR $(1.67 \pm 0.16)$ had a lesser score than the ICAR $(2.13 \pm 0.16$; Table 1; effect of tissue; $P<0.021)$. There was a numerically greater score on d $0(2.13 \pm 0.18)$ compared with d 14 $(1.67 \pm 0.18)$, but this difference did not achieve statistical significance (Table 1; effect of day; $P<0.107$ ).

Numerous studies of the apical surface of the LE and oviduct in several species including ruminants (Guillomot, 1995), laboratory animals (Quinn et al., 2020), and humans (Hafez and Ludwig, 1977; Rarani et al., 2018) have reported that the LE undergoes structural changes during the estrous or menstrual cycle that are explained by the formation and regression or rupture of apical protrusions called pinopodes. Pinopodes are short-lived extensions of the apical surface of cells with microvilli (Rarani et al., 2018; Quinn et al., 2020). We observed what we believe to be this process in the samples that we collected (Figure 3). Some cells undergo a process where the apical surface extends into the uterine lumen forming a protrusion (Figure 3B). The pinopode protrusion expands further to either flatten or push aside the microvilli (Figures 3C and D). Whether pinopodes eventually rupture to release their contents (as suggested by Figures $3 \mathrm{C}$ and $\mathrm{D}$ ) or regress back into the cell is unclear (Quinn et al., 2020). Cells whose surface is devoid of microvilli (Figure 1E) may have recently completed pinopode formation and regression and are analogous to the "craters" described previously (Guillomot and Guay, 1982). If pinopode formation and regression lead to a cratered appearance of the LE, then the process does not occur uniformly across the entire LE. We found that approximately $50 \%$ of the fields scored 1 or 2, meaning that they were neither denuded $($ score $=0$ ) nor replete with ( 3) microvilli. The CAR had fewer microvilli than the ICAR based on the scoring system that we used (Table 

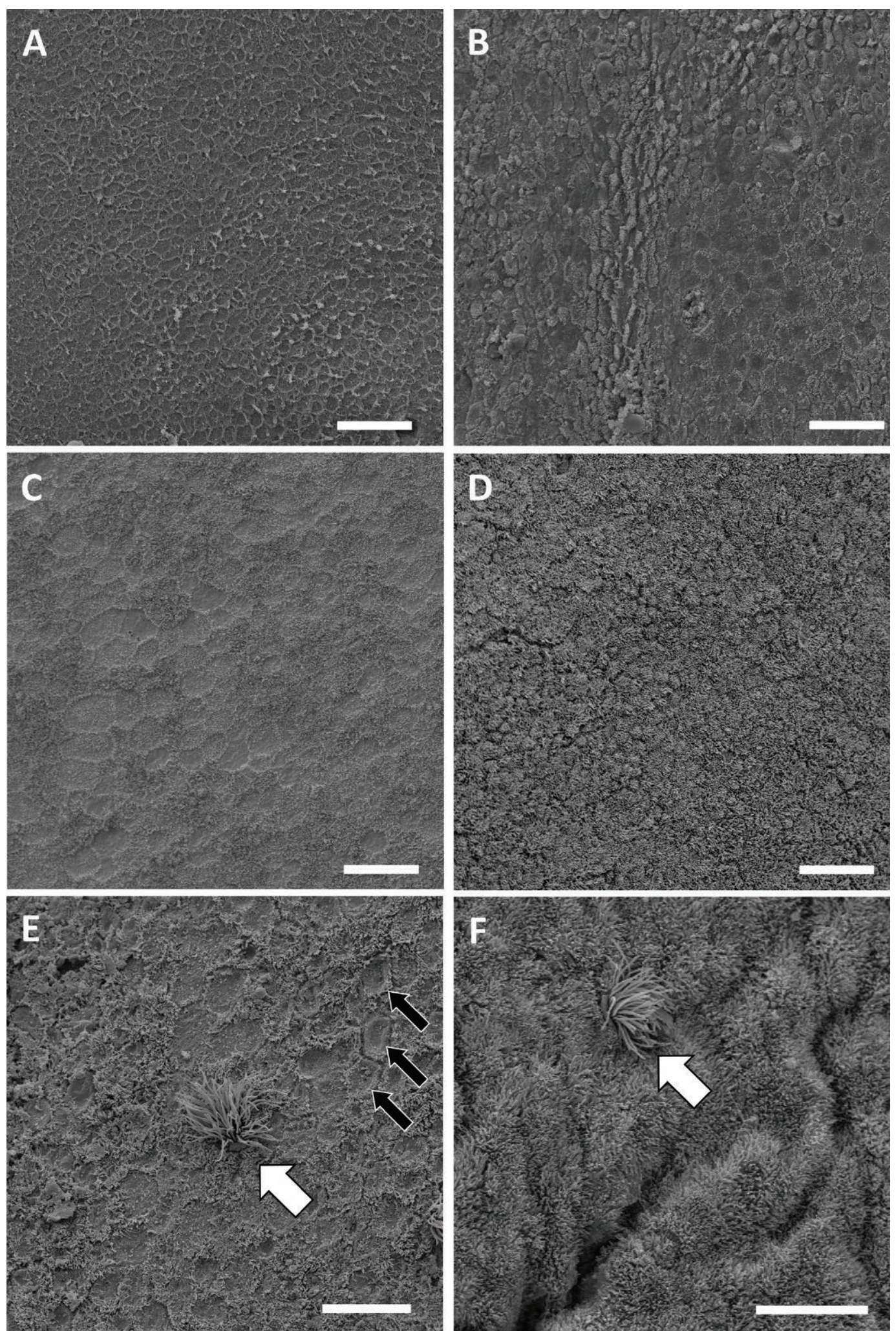

Figure 1. Scanning electron micrographs of the surface epithelium of the bovine endometrium demonstrating the morphological scoring system: (A) score $=0$ (devoid of microvilli), (B) score $=1$ ( $>0$ but $<50 \%$ covered with microvilli), (C) score $=2$ ( $\geq 50$ but $<100 \%$ covered with microvilli), and (D) score $=3$ (completely covered with microvilli). Ciliated cells (white arrow) were observed in regions that were depleted (E) or replete (F) for microvilli. Cells that lacked microvilli on their surface had a cratered appearance (E, black arrows). The scale bar for A, B, C, and $\mathrm{D}=20 \mu \mathrm{m}$ and for $\mathrm{E}$ and $\mathrm{F}=10 \mu \mathrm{m}$. Samples were collected on d $0(\mathrm{C}, \mathrm{D})$ or d $14(\mathrm{~A}, \mathrm{~B}, \mathrm{E}, \mathrm{F})$ of the estrous cycle. 

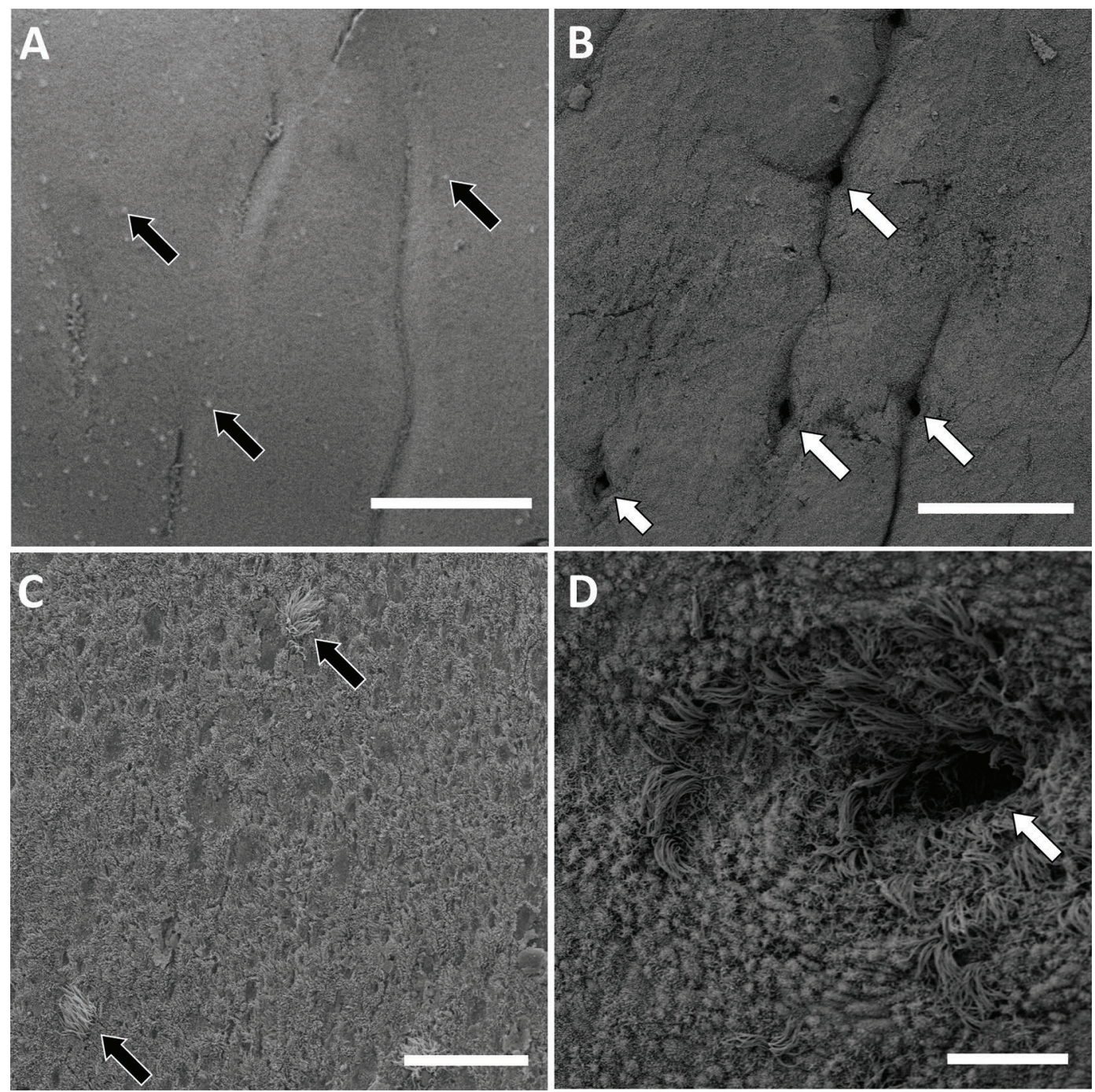

Figure 2. Scanning electron micrographs of the surface epithelium of the bovine endometrium. (A) Low magnification of caruncular tissue. Note the caruncular folds, lack of glands, and widely dispersed ciliated cells (black arrows). (B) Low magnification of intercaruncular tissue. Note the glands (white arrows) with folds between individual gland openings. (C) Higher magnification of caruncular tissue with individual ciliated cells (black arrows). (D) Higher magnification of gland opening (white arrow) showing the large number of ciliated cells at the gland opening. The scale bar for $A$ and $B=200 \mu \mathrm{m}$ and for $C$ and $D=20 \mu \mathrm{m}$. Samples were collected on d 0 (B, D) or d 14 (A, C) of the estrous cycle.

1). We cannot exclude the possibility that the difference in apical surface morphology that we observed represents functionally different cell populations within the surface LE. These different cell populations may have inherent differences in the number of microvilli on their surface that arise from alternative mechanisms that do not involve the formation and regression of pinopodes.

Most scanning electron microscopy studies of ruminant LE or oviduct have commented on the presence of apical protrusions (pinopodes) and attribute their formation during the late luteal phase to stimulatory effects of progesterone on uterine secretion (Guillomot, 1995; Quinn et al., 2020). The numerically lower micro- villi score observed for d 14 compared with d 0 (Table 1) would support the observation that a period of pinopode formation occurs during the mid-luteal phase as was suggested by several authors (Guillomot and Guay, 1982; Hyttel, 1985; Wrobel et al., 1993). The importance of the LE to the regulation of small molecules in the uterine lumen is well established (Forde et al., 2014; Bazer et al., 2015; Spencer and Hansen, 2015). Pinopodes have been assigned both endocytic and exocytic functions in the literature (Rarani et al., 2018; Quinn et al., 2020), but a functional role in pinocytosis was not supported by studies conducted in cattle (Guillomot et al., 1986). An exocytotic function where there 
is rupture of pinopodes and the release of vesicles into the uterine lumen through an apocrine mechanism has been suggested (Aitken, 1975; Guillomot, 1995), and there was evidence for this mechanism in the studied samples (Figure 3D). Collectively, the data suggest that both small molecules (through specific membranebound transporters; Forde et al., 2014; Bazer et al., 2015) and large molecules (through vesicles entering the lumen via pinopode-mediated apocrine secretion) can be transported through the LE. Uterine luminal fluid contains extracellular vesicles that are defined as membrane-bound structures containing lipids, proteins, DNA, and RNA with diverse biological functions (O'Neil et al., 2020b). Whether the pinopodes themselves or the rupture of pinopodes to release intracellular vesicles (Figure 3D) are the source of uterine extracellular vesicles should be explored. The number of extracellular vesicles within the uterine lumen increases during the late luteal phase in sheep (Burns et al., 2018; O'Neil et al., 2020a), and this coincides with the generally accepted timeframe for pinopode formation in ruminants (Guillomot, 1995).

The observations presented herein beg a central question in bovine reproduction: does the capacity to establish pregnancy affect the surface morphology of the LE? Additional questions include the following: What are the underlying mechanisms that dictate which specific regions of the uterus undergo morphological change (i.e., apical protrusion and pinopode formation)? What dictates the percentage of the uterine surface that is involved? What effect does pinopode formation have on the composition of uterine luminal fluid? How much time is required to restore the surface microvilli from the cratered surface that theoretically arises when pinopodes regress? And, given our original justification for this work, how do uterine disease and inflammation of the LE and underlying stroma affect the capacity of the uterus to undergo this unique and dynamic process?

\section{CONCLUSIONS}

Based on scanning electron microscopy of the bovine surface epithelium, the CAR and ICAR consist of cells with microvilli on their apical surface. A small number of ciliated cells are interspersed throughout the LE. The surface of the LE is not uniformly covered with microvilli but instead presents regions of LE that are replete with microvilli adjacent to those that are depleted of microvilli. There is considerable variation in the extent of microvilli depletion across individual animals. Depletion of microvilli may be explained by a normal process where apical protrusions (pinopodes) are formed and either regress back into the cell surface 

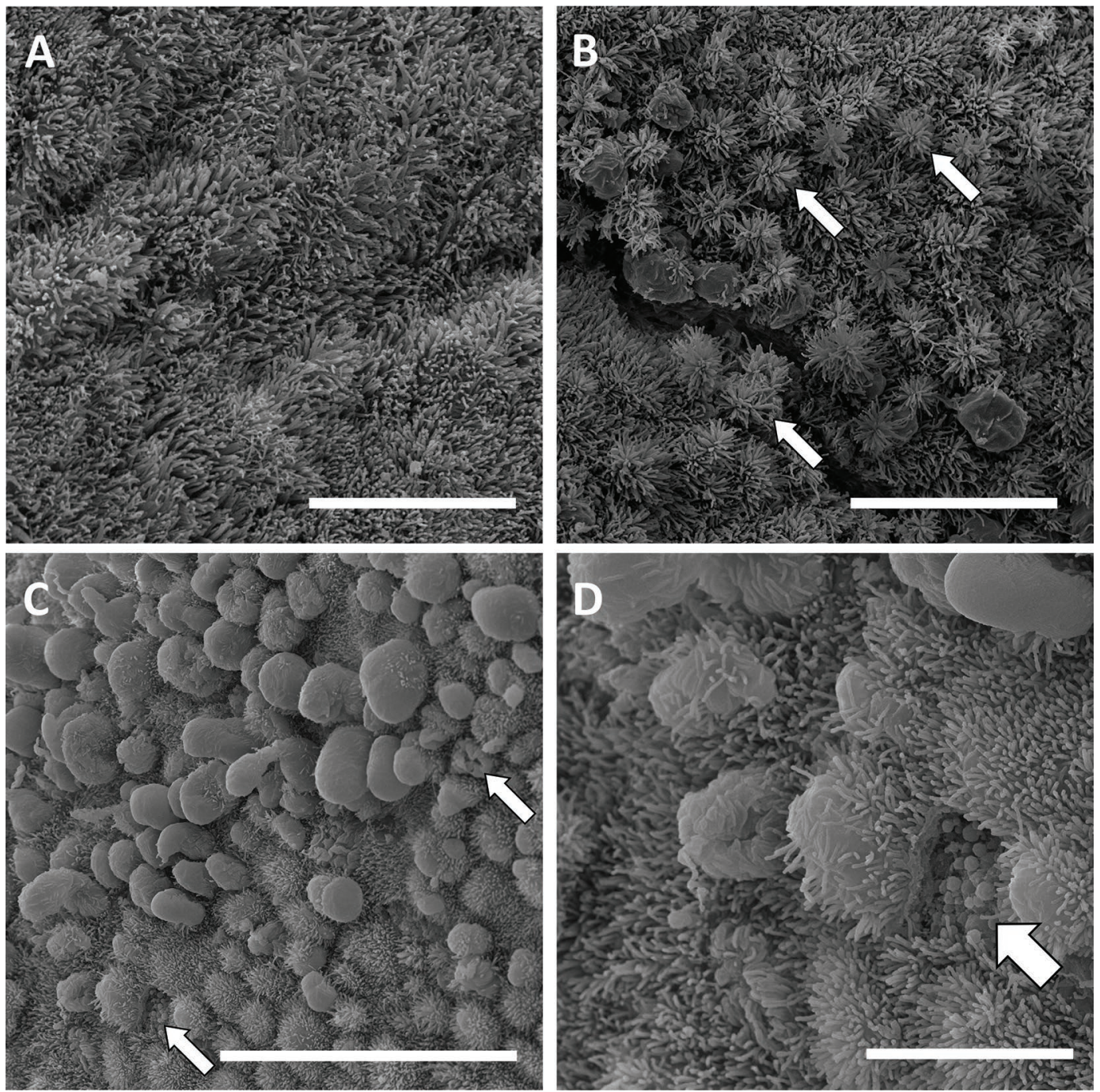

Figure 3. Scanning electron micrographs of the surface epithelium of the bovine endometrium during the formation of apical protrusions (pinopodes). (A) Endometrial surface fully covered with microvilli. (B) Pinopode formation may begin with expansion of the apical surface to form "sea-anemone-like" structures (white arrows). (C) Further expansion of the cell surface either flattens or pushes aside the microvilli, and pinopodes extend into the uterine lumen. Some cells do not appear to have an intact apical surface, perhaps because pinopodes have ruptured (white arrows). (D) Higher magnification of panel C. Vacuoles (white arrow) are exposed to the uterine lumen in a cell that does not have an intact apical surface. Scale bars: A and B $=10 \mu \mathrm{m}, \mathrm{C}=20 \mu \mathrm{m}$, and D $=5 \mu \mathrm{m}$. Samples were collected on d 0 (C, D) or d $14(\mathrm{~A}, \mathrm{~B})$ of the estrous cycle.

or break to release vacuoles into the uterine lumen. The functional significance of the LE surface morphology should be explored further in an effort to better understand factors that affect fertility in the bovine.

\section{ACKNOWLEDGMENTS}

Research reported in this publication was supported by the National Institute of Child Health and $\mathrm{Hu}-$ man Development of the National Institutes of Health (Bethesda, MD) under award number R01HD092254. The authors have not stated any conflicts of interest.

\section{REFERENCES}

Aitken, R. J. 1975. Ultrastructure of the blastocyst and endometrium of the roe deer (Capreolus capreolus) during delayed implantation. J. Anat. 119:369-384.

Akbalik, M. E., N. Liman, H. Sagsoz, and B. Guney Saruhan. 2018. Tissue distribution of some immune cells in bovine reproductive tract during follicular and luteal phase. Microsc. Res. Tech. 81:315-331. https://doi.org/10.1002/jemt.22983.

Almeida, A. P., N. Ayalon, and B. Bartoov. 1986. Bovine endometrial epithelium ultrastructure 6 and 7 days post-breeding. Anim. Reprod. Sci. 10:293-300. https://doi.org/10.1016/0378 -4320(86)90004-7.

Bazer, F. W., G. A. Johnson, and G. Wu. 2015. Amino acids and conceptus development during the peri-implantation period of preg- 
nancy. Adv. Exp. Med. Biol. 843:23-52. https://doi.org/10.1007/ 978-1-4939-2480-6_2.

Bazer, F. W., T. E. Spencer, G. A. Johnson, R. C. Burghardt, and G. Wu. 2009. Comparative aspects of implantation. Reproduction 138:195-209. https://doi.org/10.1530/REP-09-0158.

Burns, G. W., K. E. Brooks, E. V. O’Neil, D. E. Hagen, S. K. Behura, and T. E. Spencer. 2018. Progesterone effects on extracellular vesicles in the sheep uterus. Biol. Reprod. 98:612-622. https://doi .org/10.1093/biolre/ioy011.

Dadarwal, D., C. Palmer, and P. Griebel. 2017. Mucosal immunity of the postpartum bovine genital tract. Theriogenology 104:62-71. https://doi.org/10.1016/j.theriogenology.2017.08.010.

Fathalla, M. A., R. M. Liptrap, and H. D. Geissinger. 1975. Combined scanning electron and light microscopy of biopsy samples of bovine uterus. Can. J. Comp. Med. 39:457-461.

Forde, N., C. A. Simintiras, R. Sturmey, S. Mamo, A. K. Kelly, T. E. Spencer, F. W. Bazer, and P. Lonergan. 2014. Amino acids in the uterine luminal fluid reflects the temporal changes in transporter expression in the endometrium and conceptus during early pregnancy in cattle. PLoS One 9:e100010. https://doi.org/10.1371/ journal.pone.0100010.

Gilbert, R. O. 2019. Symposium review: Mechanisms of disruption of fertility by infectious diseases of the reproductive tract. J. Dairy Sci. 102:3754-3765. https://doi.org/10.3168/jds.2018-15602.

Guillomot, M. 1995. Cellular interactions during implantation in domestic ruminants. J. Reprod. Fertil. Suppl. 49:39-51.

Guillomot, M., K. J. Betteridge, D. Harvey, and A. K. Goff. 1986. Endocytotic activity in the endometrium during conceptus attachment in the cow. J. Reprod. Fertil. 78:27-36. https://doi.org/10 $.1530 /$ jrf.0.0780027.

Guillomot, M., J.-E. Fléchon, and S. Wintenberger-Torres. 1981. Conceptus attachment in the ewe: An ultrastructural study. Placenta 2:169-182. https://doi.org/10.1016/s0143-4004(81)80021-5.

Guillomot, M., and P. Guay. 1982. Ultrastructural features of the cell surfaces of uterine and trophoblastic epithelia during embryo attachment in the cow. Anat. Rec. 204:315-322. https://doi.org/10 $.1002 /$ ar.1092040404.

Hafez, E. S. E., and H. Ludwig. 1977. Scanning Electron Microscopy of the Endometrium. R. M. Wynn, ed. Springer US, Boston, MA.

Hantak, A. M., I. C. Bagchi, and M. K. Bagchi. 2014. Role of uterine stromal-epithelial crosstalk in embryo implantation. Int. J. Dev. Biol. 58:139-146. https://doi.org/10.1387/ijdb.130348mb.

Hyttel, P. 1985. The epithelium of uterine biopsies from cyclic dairy cattle: Ultrastructure and endocytotic activity. Acta Anat. (Basel) 123:93-100. https://doi.org/10.1159/000146046.

Kelleher, A. M., F. J. DeMayo, and T. E. Spencer. 2019. Uterine glands: Developmental biology and functional roles in pregnancy. Endocr. Rev. 40:1424-1445. https://doi.org/10.1210/er.2018 $-00281$

Koyama, H., D. Shi, and T. Fujimori. 2019. Biophysics in oviduct: Planar cell polarity, cilia, epithelial fold and tube morphogenesis, egg dynamics. Biophys. Physicobiol. 16:89-107. https://doi.org/10 .2142 /biophysico.16.0_89.

LeBlanc, S. J. 2014. Reproductive tract inflammatory disease in postpartum dairy cows. Animal 8(Suppl. 1):54-63. https://doi.org/10 $1017 /$ S1751731114000524

Moraes, J. G. N., S. K. Behura, J. V. Bishop, T. R. Hansen, T. W. Geary, and T. E. Spencer. 2020a. Analysis of the uterine lumen in fertility-classified heifers: II. Proteins and metabolites. Biol. Reprod. 102:571-587. https://doi.org/10.1093/biolre/ioz197.

Moraes, J. G. N., S. K. Behura, T. W. Geary, and T. E. Spencer. 2020b. Analysis of the uterine lumen in fertility-classified heifers: I. Glucose, prostaglandins, and lipids. Biol. Reprod. 102:456-474. https://doi.org/10.1093/biolre/ioz191.

O'Neil, E. V., G. W. Burns, C. R. Ferreira, and T. E. Spencer. 2020a. Characterization and regulation of extracellular vesicles in the lumen of the ovine uterus. Biol. Reprod. 102:1020-1032. https://doi .org/10.1093/biolre/ioaa019.

O'Neil, E. V., G. W. Burns, and T. E. Spencer. 2020b. Extracellular vesicles: Novel regulators of conceptus-uterine interactions? Theriogenology 150:106-112. https://doi.org/10.1016/j.theriogenology 2020.01.083.

Ott, T. L. 2019. Symposium review: Immunological detection of the bovine conceptus during early pregnancy. J. Dairy Sci. 102:37663777. https://doi.org/10.3168/jds.2018-15668.

Quinn, K. E., B. C. Matson, M. Wetendorf, and K. M. Caron. 2020 Pinopodes: Recent advancements, current perspectives, and future directions. Mol. Cell. Endocrinol. 501:110644. https://doi.org/10 .1016/j.mce.2019.110644.

Rarani, F. Z., F. Borhani, and B. Rashidi. 2018. Endometrial pinopode biomarkers: Molecules and microRNAs. J. Cell. Physiol. 233:91459158. https://doi.org/10.1002/jcp.26852.

Sandra, O., G. Charpigny, L. Galio, and I. Hue. 2017. Preattachment embryos of domestic animals: Insights into development and paracrine secretions. Annu. Rev. Anim. Biosci. 5:205-228. https://doi .org/10.1146/annurev-animal-022516-022900.

Sheldon, I. M. 2004. The postpartum uterus. Vet. Clin. North Am. Food Anim. Pract. 20:569-591. https://doi.org/10.1016/j.cvfa 2004.06.008.

Spassky, N., and A. Meunier. 2017. The development and functions of multiciliated epithelia. Nat. Rev. Mol. Cell Biol. 18:423-436. https: //doi.org/10.1038/nrm.2017.21.

Spencer, T. E., N. Forde, and P. Lonergan. 2016. The role of progesterone and conceptus-derived factors in uterine biology during early pregnancy in ruminants. J. Dairy Sci. 99:5941-5950. https://doi .org/10.3168/jds.2015-10070.

Spencer, T. E., and T. R. Hansen. 2015. Implantation and establishment of pregnancy in ruminants. Adv. Anat. Embryol. Cell Biol. 216:105-135. https://doi.org/10.1007/978-3-319-15856-3_7.

Walton, K. D., A. M. Freddo, S. Wang, and D. L. Gumucio. 2016 Generation of intestinal surface: An absorbing tale. Development 143:2261-2272. https://doi.org/10.1242/dev.135400.

Wathes, D. C. 2012. Mechanisms linking metabolic status and disease with reproductive outcome in the dairy cow. Reprod. Domest. Anim. 47(Suppl. 4):304-312. https://doi.org/10.1111/j.1439-0531 .2012.02090.x.

Wrobel, K. H., R. Kujat, and G. Fehle. 1993. The bovine tubouterine junction: General organization and surface morphology. Cell Tissue Res. 271:227-239. https://doi.org/10.1007/BF00318609.

Yániz, J. L., F. Lopez-Gatius, P. Santolaria, and K. J. Mullins. 2000. Study of the functional anatomy of bovine oviductal mucosa. Anat. Rec. 260:268-278. https://doi.org/10.1002/1097 -0185(20001101)260:3<268::AID-AR60>3.0.CO;2-L 